\title{
Tumour-induced osteomalacia: a literature review and a case report
}

\author{
Jolanta Dadoniene ${ }^{1,2,3}$, Marius Miglinas ${ }^{1,4}$, Dalia Miltiniene ${ }^{1,2,3}$, Donatas Vajauskas ${ }^{1,5}$, Dmitrij Seinin ${ }^{6}$, \\ Petras Butenas ${ }^{7}$ and Tomas Kacergius ${ }^{1^{*}}$
}

\begin{abstract}
Tumour-induced osteomalacia $(\mathrm{TIO})$ is a rare paraneoplastic syndrome characterised by severe hypophosphataemia and osteomalacia, with renal phosphate wasting that occurs in association with tumour. The epidemiology likewise aetiology is not known. The clinical presentation of TIO includes bone fractures, bone and muscular pains, and sometimes height and weight loss. TIO may be associated with mesenchymal tumours which may be benign or malignant in rare cases. Mesenchymal tumour itself may be related to fibroblast growth factor 23 (FGF23), which is responsible for hypophosphataemia and phosphaturia occurring in this paraneoplastic syndrome.

Hypophosphataemia, phosphaturia and elevated alkaline phosphatase are the main laboratory readings that may lead to more precise investigations and better diagnosis. Finding the tumour can be a major diagnostic challenge and may involve total body magnetic resonance imaging, computed tomography and scintigraphy using radiolabelled somatostatin analogue. The treatment of choice for $\mathrm{TIO}$ is resection of a tumour with a wide margin to insure complete tumour removal, as recurrences of these tumours have been reported. We provide here an overview on the current available $\mathrm{TIO}$ case reports and review the best practices that may lead to earlier recognition of $\mathrm{TIO}$ and the subsequent treatment thereof, even though biochemical background and the long-term prognosis of the disease are not well understood. This review also includes a 4-year-long history of a patient that featured muscular pains, weakness and multiple stress fractures localised in the hips and vertebra with subsequent recovery after tumour resection. Because the occurrence of such a condition is rare, it may take years to correctly diagnose the disease, as is reported in this case report.
\end{abstract}

Keywords: Tumour-induced osteomalacia, Hypophosphataemia, Fibroblast growth factor 23

\section{Background}

Tumour-induced osteomalacia (TIO) is a rare paraneoplastic syndrome clinical presentation of which includes bone fractures, bone and muscular pains, and sometimes loss of height and even weight. Weight loss is unusual, but sometimes observed, and could be explained by general debilitated state of the patient with consequent poor nutrient intake and loss of muscle mass [1,2]. Most of them are believed to be benign, although cases judged to be histopathologically malignant have been also described [3-6]. Mesenchymal tumour itself may be related to fibroblast growth factor 23 (FGF23), which is responsible for

\footnotetext{
* Correspondence: tomas.kacergius@mf.vu.lt

${ }^{1}$ Faculty of Medicine, Vilnius University, Ciurlionio 21, Vilnius, Lithuania Full list of author information is available at the end of the article
}

hypophosphataemia and phosphaturia occurring in this paraneoplastic syndrome. Hypophosphataemia, phosphaturia and elevated alkaline phosphatase are the main laboratory readings that may lead to more precise investigations and better diagnosis. Although several hundreds of cases have been reported since 1947 when McCance et al. described the first TIO case [7], majority of clinicians, radiologists and pathologists are not aware of this rare disease with only several cases described in rheumatology practice $[5,6,8-14]$. We provide an overview of the current literature available on TIO case reports and review the best practice for the diagnosis and treatment. We also present here a 4-year-long case study of a patient who was eventually diagnosed with TIO. We report the initial presentation of the disease and the steps leading to TIO diagnosis.

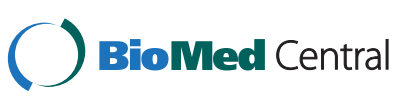

(c) 2016 Dadoniene et al. Open Access This article is distributed under the terms of the Creative Commons Attribution 4.0 International License (http://creativecommons.org/licenses/by/4.0/), which permits unrestricted use, distribution, and reproduction in any medium, provided you give appropriate credit to the original author(s) and the source, provide a link to the Creative Commons license, and indicate if changes were made. The Creative Commons Public Domain Dedication waiver (http://creativecommons.org/publicdomain/zero/1.0/) applies to the data made available in this article, unless otherwise stated. 


\section{Review}

\section{Disease name and definition}

TIO is characterised by severe hypophosphataemia and osteomalacia, with renal phosphate wasting that occurs in association with tumour. TIO also is called oncogenic hypophosphatemic osteomalacia (M83.8) and appears in the portal for rare diseases and orphan drugs under that name (ORPHA352540). It was first described in 1947 by Robert McCance, who reported a patient with pain, weakness, gait abnormalities, and low phosphorus levels. The patient was treated with high doses of vitamin $\mathrm{D}$, but the symptoms did not completely resolve until a tumour in femur bone was removed [7].

The first person to clearly recognise that the disease was the result of a "rachitogenic" substance was Andrea Prader. In 1959, he described an 11 1/2-year-old girl who developed severe rickets over the course of a year. Evaluation showed decreased tubular phosphate reabsorption but otherwise normal kidney function. A tumour, classified as a giant cell granuloma, was identified in a rib and removed resulting in healing of rickets [15].

\section{Epidemiology}

The prevalence of the disease is not known. Since the association between phosphate reabsorption and tumour was first made, more than 300 cases of TIO have been reported in the literature [16].

\section{Pathogenesis}

The first evidence of a circulating factor that could cause phosphate wasting in phosphaturic disorders such as TIO was demonstrated in a set of experiments in mice by Meyer et al. and Nesbitt et al. [17, 18]. The first evidence to support this concept in humans was the experiment by Miyauchi et al. in which a tumour removed from a patient and transplanted into nude mice caused hypophosphatemia [19].

FGF23 was first identified as the phosphaturic substance when mutations in FGF23 were linked to autosomaldominant hypophosphatemic rickets (ADHR) [20, 21]. Soon after that, elevations in serum FGF23 were found in $\mathrm{TIO}$ and it was shown that FGF23 binds to target proximal tubule cells via FGF receptor and inhibits renal phosphate reabsorption [21]. The primary transport protein responsible for phosphate reabsorption in the kidney is the type II sodium-phosphate co-transporters (NaPi-IIa and $\mathrm{NaPi}$-IIc) localised in the proximal tubule. High circulating FGF-23 levels reduce the expression of the co-transporters, leading to renal phosphate wasting $[16,22-24]$. FGF23 is also a regulatory hormone for 1.25-vitamin D and leads to a decreased concentration of the vitamin in blood [25].

Excessive FGF23 action causes several hypophosphatemic diseases, including TIO, X-linked hypophosphatemic rickets (XLHR), autosomal dominant and recessive hypophosphatemic rickets (ADHR and ARHR) [26-28]. Under physiological conditions, FGF23 is secreted predominantly by bone and undergoes degradation by proteolytic enzymes [27]. By contrast, tumours secrete FGF23 to concentrations that are several hundred-fold higher than normal levels, leading to dysregulation of FGF23 degradation pathway [29].

\section{Histopathology}

The tumours associated with TIO are usually small and mesenchymal in origin [30]. The prototypical phosphaturic mesenchymal tumour (mixed connective tissue variant) contains neoplastic cells that are spindled to stellate in shape, normochromatic with small nuclei and indistinct nucleoli. The nuclear grade is low, and mitotic activity is usually absent or very low. The cells are typically embedded within a myxoid or myxo-chondroid matrix with "grungy" calcification that can resemble chondroid or osteoid. Numerous osteoclast-like giant cells are a frequent finding, and mature fat and even lamellar bone may also be seen. A prominent feature of these tumours is an elaborate intrinsic microvasculature with an admixture of vessel size and vascular pattern [3]. The most common diagnosis for these tumours has been hemangiopericytoma, but it has also included hemangioma, sarcomas, ossifying fibromas, granulomas, giant cell tumours and osteoblastomas.

Weidner in 1991 was the first to propose a classification system based on the histological findings of 16 cases of TIO and designated the tumours as phosphaturic mesenchymal tumours [31]. TIO tumours can be further subdivided into four categories: mixed connective tissue variant (phosphaturic mesenchymal tumour mixed connective tissue variant-PMTMCT), osteoblastoma-like variant, non-ossifying fibroma-like variant, and ossifying fibroma-like variant. The PMTMCT group is diagnosed in $70-80 \%$ of $\mathrm{TIO}$ cases and comprises neoplasias containing primitive stromal cells, prominent vessel, and osteoclast-like giant cells. PMTMCT tumours usually occur in bones or soft tissues and are typically benign in behaviour, but malignant variants have already been described. Malignant examples show frankly sarcomatous features, such as a high nuclear grade, high cellularity, elevated mitotic activity and necrosis [3, 6, 22, 32]. The remaining three groups tend to occur in bones and were also typically benign in behaviour.

When testing antigen expression, FGF23 is positive in about $70 \%$ of all the cases studied, and the proliferating cells within the tumour are usually the source of FGF23 [3]. Somatostatin receptors have also been found to be present in many TIO tumours [33-35].

While typically benign, malignant presentation and metastases can occur $[4,5,36]$. While metastases are 
rare, infiltration of surrounding connective tissue is typically present, which has significant implications for surgical management and emphasises importance for wide surgical margins to avoid persistence or reoccurrence.

Regardless of tumour morphology, the hallmark of the diagnosis is the association of the tumour with the clinical syndrome of TIO, which includes an elevation in plasma FGF23 and its disappearance after tumour resection.

\section{Clinical evaluation and diagnosis confirmation}

Quoting Jiang et al. who reviewed 308 tumour-induced osteomalacia cases reported in English literature between 1987 and 2011, about $46 \%$ of reported cases of TIO have occurred in females and $56 \%$ in males, with a mean age of 45.3 years when definitive diagnosis was made [37]. Within the reported cases TIO, tumours originate in bones (40\%) and soft tissues (55\%). Most tumours are reported to occur in the thigh and femur $(22.7 \%)$, craniofacial region (20.7\%), ankle and foot (8.8\%), pelvis (8.2\%), tibia and fibula (6.5 \%) and arms (6.5 \%). The less common locations are the vertebra, knee, hand, chest, abdomen, groin, perineum and gluteal region [3, 37, 38]. Some tumours can even be located in organs such as the liver, tongue, thyroid and lungs [1, 3, 4, 39]. A few patients $(2 \%)$ are reported as having tumours in more than one site, sometimes representing metastases [37].

Patients with TIO often present with many years of symptoms before they are diagnosed. The symptoms usually are nonspecific and often progressive. Common complaints are bone pain, muscle weakness, reduced height, and multiple fractures, primarily in the ribs, vertebral bodies, and femoral neck [22, 37]. The patients are often misdiagnosed with a variety of musculoskeletal, rheumatologic diseases and sometimes even psychiatric disorders [16, 40]. Hypophosphatemia caused by impaired renal phosphate reabsorption is the biochemical hallmark of the disease. Additional laboratory tests can be helpful in making the diagnosis of TIO. The typical biochemical pattern of TIO includes normal or low levels of 1,25-dihydroxyvitamin D, elevated levels of alkaline phosphatase (reflecting osteoblast hyperactivity and active bone remodelling) and normal circulating levels of calcium and parathormone (PTH). In some cases, PTH can be particularly high reflecting secondary hyperparathyroidism, which is a normal response to low 1,25vitamin D caused by elevated FGF23 [22, 23, 41].

Differential diagnosis should always include renal Fanconi's syndrome-a disorder of the proximal renal tubules, leading to impaired phosphate reabsorption and hypophosphatemia. This syndrome may be genetic in origin or it may occur as a complication of myeloma, amyloidosis, or Sjogren's syndrome. It can also occur with certain medications or heavy metal poisoning. The diagnosis can be confirmed by normal levels of FGF23 along with the presence of glycosuria, hypokalaemia, and metabolic acidosis [2].

Once the diagnosis of an FGF23-dependent, phosphate wasting disorder is made, a thorough history can aid in excluding the genetic causes, such as XLHR, ADHR and ARHR. Genetic testing can also be done.

Having narrowed the diagnosis to TIO, a careful physical examination should be performed, as the tumours that cause TIO can sometimes be found in the subcutaneous tissue [42]. As tumours can arise in bone or soft tissue, occur from head to toe and are typically very small in size and slow-growing, locating these tumours is often quite challenging. As a result, the time from osteomalacia to identifying the associated tumour averages a period of 5 years [43].

Finding the tumours can be a major diagnostic challenge and may involve total body magnetic resonance imaging (MRI); as tumours can occur anywhere in the body, it is important to scan the whole body, including extremities, which is often excluded in routine nuclear medicine imaging [44], computed tomography (CT), scintigraphy using radiolabelled somatostatin analogue (such as $99 \mathrm{mTc}$-Tektrotyd) and positron emission tomography, with computed tomography: fluorodeoxyglucose (18FFDG) PET/CT and galium (68Ga) DOTATATE PET/CT and selective venous sampling for FGF23 [44-51].

A stepwise approach is advocated, first performing functional tests. Tumours associated with osteomalacia variably express five somatostatin receptors (SSTR1-5), allowing SSTR-based functional imaging by somatostatin analogue scintigraphy or positron emission tomography [33, 46, 52, 53]. Octreotide is somatostatin analogue used in treatment of some neuroendocrine tumours and acromegaly. It is possible to radiolabel the somatostatin analogue in an attempt to detect tumours that express somatostatin receptors [38, 47, 52]. Octreotide scanning is commonly performed with ${ }^{111}$ In-labelled pentatreotide. Octreotide scintigraphy is successfully used to locate tumours in up to $95 \%$ of patients with TIO [37]. It may even be possible to use this technology therapeutically in radioimmunoguided surgery or labelling of octreotide with a beta-emitting radionuclide [47]. Despite this success, there are several limitations of this imaging technology. Inflammatory reactions or a fracture will be associated with a false-positive scan. Somatostatin analogues scintigraphy is also limited by planar two-dimensional imaging and relatively poor spatial resolution, which is particularly problematic given that TIO tumours are often very small. Single-photon emission tomography (SPECT) or hybrid SPECT/CT enables three-dimensional imaging and better tumour contrast but is time-consuming and therefore limited to areas of suspected abnormality rather than a whole body survey [35]. Somatostatin analogue positron emission tomography 
can dramatically improve the spatial resolution and lesion detectability [54].

Anatomic imaging (radiography, CT and MRI) should be performed to confirm the location of the tumour after suspicious lesions had been identified by functional imaging [13]. High-resolution magnetic resonance imaging of the whole body is the currently proposed method of choice to confirm the location of the tumour [41].

Despite all of the advances in imaging that are available today, tumour localization may not be successful. If this is the case, imaging studies should be repeated every $1-2$ years.

\section{Treatment}

The treatment of choice for TIO is resection of a tumour with a wide margin to insure complete tumour removal, as recurrences of these tumours have been reported $[4,9,36]$. Tumour removal is always curative, and following complete resection of the tumour, the recovery and improvement of the patients is relatively quick, FGF23 disappears rapidly from the circulation, and serum phosphate returns to normal by day 5 post operation [55]. Most patients feel better within days to weeks of tumour removal. Bone healing starts immediately, but depending on the severity of the disease, it may take up to a year for a more significant clinical improvement to be seen.

In case of incompletely resected tumours, subsequent radiotherapy can be used to avoid recurrence or metastasis (41). Late recurrence due to metastatic disease is rare but possible. This probably occurs in less than $5 \%$ of the patients with TIO [3,36]. Lung is a common site for metastasis. The course after metastasis is quite variable, and survival of up to 30 years has been reported [56]. There is no chemotherapeutic regimen with any demonstrated efficacy in treating metastatic TIO. Radiofrequency ablation (RFA) has been reported as a possible treatment modality [14].

When the tumour cannot be localised or is not surgically resectable, medical therapy with phosphate supplementation and calcitriol or alfacalcidol is used. Treatment with octreotide is an alternative form of medical therapy that may be considered. In one case report, phosphate wasting and hypophosphatemia were corrected with octreotide therapy; this effect was presumably mediated by somatostatin receptor expression by the tumour, which was demonstrated by octreotide scintigraphy [43]. However, not all patients respond to octreotide [33, 57]. Treatment with the calcium-sensing receptor agonist, cinacalcet, could also be effective for the treatment of TIO patients by inducing hypoparathyroidism and thus increasing renal phosphate reabsorption [58].

Anti-FGF23 antibody is being studied as a novel therapy for FGF23-related hypophosphatemic diseases [59]. Results of phase I study of single injection of humanized
anti-FGF23 antibody for adult patients with XLHR were recently published. This antibody therapy may be useful for patients with TIO $[60,61]$.

\section{Prognosis}

The prognosis depends on detecting the tumour and possibility to remove it widely. The tumours when detected are typically benign in most of the cases. The symptoms disappear and the healing of the bones begin after total removal of the tumour. Nevertheless, the follow-up should be continued because the delayed metastasis can occur as it was described in few cases.

\section{Case report}

A 48-year-old man was first seen by a rheumatologist in the beginning of 2011 because of progressing weakness, $10 \mathrm{~kg}$ weight loss during the recent year, diminishing height and muscular and bone pain in arms, lower back and chest which severely limited his movements. The patient felt unhealthy since 2009; however, his life history had no recorded health-related problems except for rib fracture during a car accident in his childhood and many years of smoking. His family history revealed that his father died of pancreatic cancer, his brother died of oncohematology condition and his mother lives with oncohematological disease. At the time of investigation, he was $180 \mathrm{~cm}$ tall (being $184 \mathrm{~cm}$ when healthy) and weighted $73 \mathrm{~kg}\left(\mathrm{BMI}=22.5 \mathrm{~kg} / \mathrm{m}^{2}\right)$. Physical examination revealed scoliosis and kyphosis of the spine, overall weakness, weakness in muscles and pain in both arms when palpating. The laboratory investigations showed no inflammation, and the only abnormality in serological readings was elevated alkaline phosphatase-248 U/l (normal values, 40-150) due to its bone-specific fraction comprising $80.5 \%$ (Table 1 ). The radiology of the spine revealed compressive fracture in Th11-Th12, which was confirmed by the following computed tomography (CT) scan and magnetic resonance imaging (MRI) readings as well. Bone mineral density was $0.840 \mathrm{~g} / \mathrm{cm}^{2}$ indicating osteopenia. Because of the family history, the patient underwent urological examination and ultrasound of the thyroid gland, liver, spleen and prostate. His lung CT scan was inconspicuous with small atelectasis in lower segments. He was also referred to a haematologist and endocrinologist, but after examination, both myeloma and parathyroid disease were excluded, although autoimmune thyroiditis due to raised autoantibodies against thyroid tissue was diagnosed. No treatment except for painkillers was prescribed.

With continuing weight and height loss together with bone and muscle pain, the patient was hospitalised at the Department of Rheumatology for thorough examination in November 2011. The alkaline phosphatase remained elevated and hypophosphatemia $0.48 \mathrm{mmol} / \mathrm{l}$ 
Table 1 The sequence of laboratory findings from the beginning of disease

\begin{tabular}{|c|c|c|c|c|c|c|c|c|}
\hline \multirow[b]{2}{*}{ Sequence of analysis } & \multicolumn{2}{|l|}{2011} & \multicolumn{2}{|l|}{2012} & \multirow{2}{*}{$\begin{array}{l}2013 \\
1 s t\end{array}$} & \multicolumn{2}{|l|}{2014} & \multirow{2}{*}{$\begin{array}{l}2015 \\
\text { (1 year after hip arthroplasty) }\end{array}$} \\
\hline & $\overline{1 s t}$ & 2 2nd & $\overline{1 s t}$ & 2nd & & $\overline{1 s t}$ & 2 2nd & \\
\hline \multicolumn{9}{|l|}{ Laboratory findings } \\
\hline Phosphate $(0.87-1.45 \mathrm{mmol} / \mathrm{l})$ & 0.48 & & & & & 0.52 & 0.36 & 1.19 \\
\hline $24 \mathrm{~h}$ urine sample phosphate (12.9-42.0 mmol/24 h) & 26.49 & & & & & 17.97 & & $\% \mathrm{TPR}=90.52^{\mathrm{a}}$ \\
\hline Calcium (2.15-2.50 mmol/l) & 2.25 & & 2.37 & & & 2.42 & 2.40 & 2.48 \\
\hline Ionised calcium (1.05-1.30 mmol/l) & 1.12 & & 1.16 & & & 1.30 & 1.09 & \\
\hline Alkaline phosphatase $(40-150 \mathrm{U} / \mathrm{l})$ & 248 & 274 & 310 & 257.25 & 297.7 & 319.19 & 279 & 85.97 \\
\hline $25-\mathrm{OH}$ vitamin $\mathrm{D}(75-100 \mathrm{nmol} / \mathrm{l})$ & 78.4 & & 54.68 & 47.93 & 77.70 & 85.83 & 72.3 & 44.42 \\
\hline Parathyroid hormone (1.6-7.2 pmol//) & & & 6.07 & 8.10 & & 19.9 & 12.01 & \\
\hline FGF-23 26-110 U/I & & & & & & 589 & & $\begin{array}{l}104 \text { (measured } 3 \text { months after } \\
\text { hip arthroplasty) }\end{array}$ \\
\hline
\end{tabular}

a $\%$ TPR $=90.52-$ calculated according to the formula: $100 \times(1-($ (urine phosphate/urine creatinine $) \times($ serum creatinine/serum phosphate) $)) .100 \times(1-((45.06 / 28.521) \times$ $(0.07 / 1.17)))$ and was found to be in normal range between 85 and $95 \%$. Numbers are entered in millimoles per liter

(normal values, $0.87-1.45$ ) was documented for the first time. The 24-h urine sample phosphaturia showed normal phosphate clearance $26.5 \mathrm{mmol} / 24 \mathrm{~h}$ (normal values, $12.9-42.0 \mathrm{mmol} / 24 \mathrm{~h}$ ) and subsequent phosphate readings in urine were within normal values as well. Vitamin D levels, calcium and ionised calcium readings were found within the normal values: vitamin $\mathrm{D}$ being $78.4 \mathrm{nmol} / \mathrm{l}$ (normal values, 75-100); calcium $2.25 \mathrm{mmol} / \mathrm{l}$ (normal values, 2.15-2.50); and ionised calcium $1.12 \mathrm{mmol} / \mathrm{l}$ (normal values, 1.05-1.30); nevertheless, he used periodically prescribed bone mineral supplements from the beginning of disease. The radiology of spine showed a new compressive fracture in the level Th7-Th8 in addition to the old fracture, which was later confirmed by $\mathrm{CT}$ scan. Whole body bone scintigraphy with $99 \mathrm{mTc}-\mathrm{MDP} 550 \mathrm{MBq}$ showed increased focal uptake of a radiotracer in the left shoulder and in the ribs on both sides due to osteoblastic process and reduced uptake in right femoral on SPEC/CT sclerotic bone lesion without tumour at that time or Morbus Paget specificity (Fig. 1). At that time, undifferentiated bone structural changes (M85.9) were diagnosed because of compressive fractures in spine, increased bone specific fraction of alkaline phosphatase and no evidence found for oncologic disease.

In February 2012, the avascular necrosis of both femur heads with osteosclerotic locus in the right femur of unknown origin was found by MRI. During routine follow-up in 2013, additional compressions were found in spine $\mathrm{CT}$, now overtaking the segment from $\mathrm{T} 5$ to T12. The bone density continued to diminish up to $0.76 \mathrm{~g} / \mathrm{cm}^{2}$ in the hip and spine, and alkaline phosphatase readings remained elevated. The antiosteoporotic treatment was started at that time with ac. zolendronicum $(5 \mathrm{mg} / 100 \mathrm{ml})$ administered intravenously and repeated after a year of interval but with no clinical or laboratory improvement. It was discontinued and switched to oral
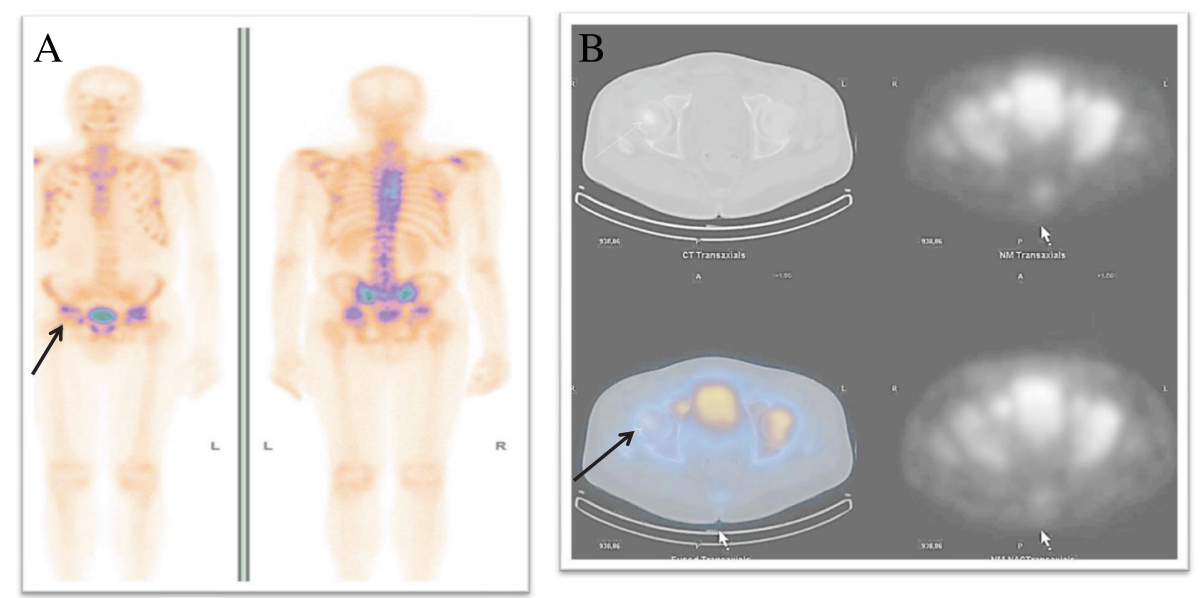

Fig. 1 a Whole body bone scintigraphy 99mTc-MDP. Moderate uptake in the right shoulder, on both sides of the ribs due to osteoblastic lesions. Reduces radiotracer uptake in right femoral head (long arrow). b 99mTc-MDP SPECT/CT of the pelvis. Reduced radiotracer uptake in right femur head, corresponding sclerotic lesion on CT (long arrow) (year 2011) 

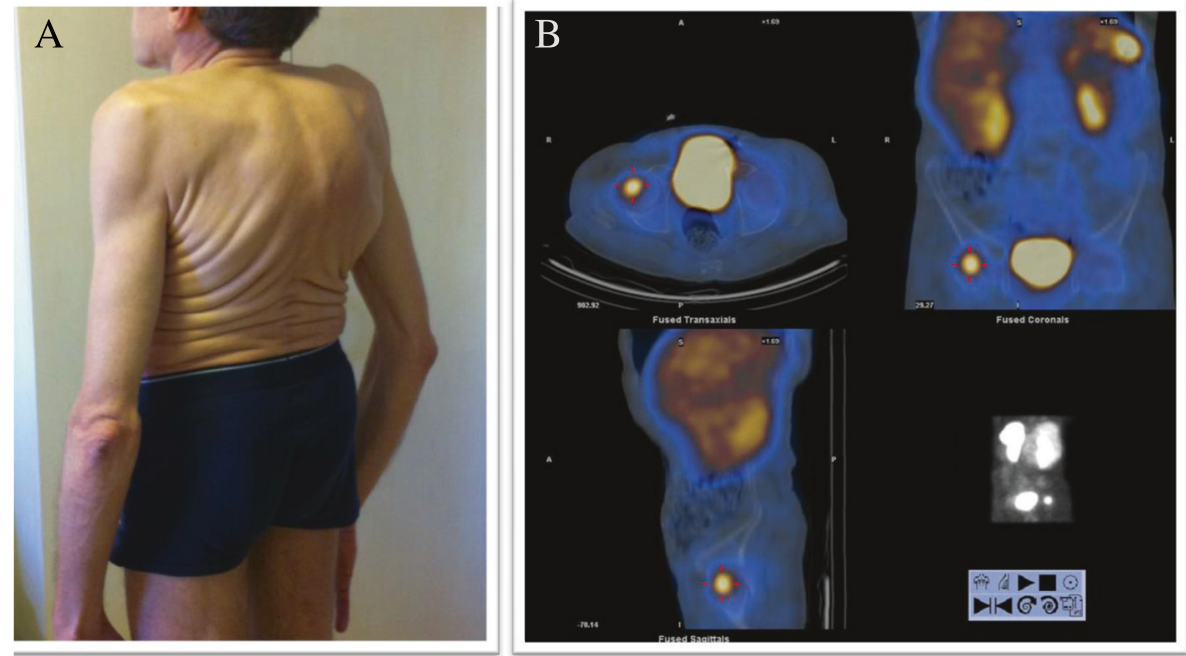

Fig. 2 a The posture before the right hip endoprosthesis operation and tumour extirpation. The patient has given the written consent for his medical findings and photos to be published. b $99 \mathrm{mTc}-T e k t r o t y d$ whole body scintigraphy. Intensive, focal radiotracer uptake in right femur head ( red markers around) (year 2014)

bisphosphonate. Natrium risedronate was initially prescribed in dosage of $35 \mathrm{mg}$ once per week and subsequently increased to $35 \mathrm{mg}$ per day but was discontinued in the fall 2014 because of no effect.

During the time period of almost 4 years, the clinical condition continued to worsen with a loss of height for $15 \mathrm{~cm}$ and weight for $20 \mathrm{~kg}$ from year 2011 now standing for $165 \mathrm{~cm}$ height and $53 \mathrm{~kg}$ weight $\left(B M I=23.1 \mathrm{~kg} / \mathrm{m}^{2}\right)$, permanent pain in chest and hips, progressing breathing discomfort, muscular weakness, inability to bend below knees and posture change (Fig. 2, photo taken in October 2014). Taking in account hypophosphatemia, elevated alkaline phosphatase from the beginning of disease, compressive fractures and avascular necrosis in femur heads, the differential diagnosis was broadened to acquired
Fanconi's syndrome, X-chromosome-linked hypophosphataemia and phosphaturic tumour-induced osteomalacia. To rule out Fanconi's syndrome, the heavy metals analysis for copper, lead, cadmium and mercury were ordered and were found to be in normal ranges: copper $15.7 \mu \mathrm{mol} / \mathrm{l}$ ( $n, 11-22)$, lead $9.60 \mu \mathrm{g} / \mathrm{l}(n, 0-90)$, cadmium $0.8 \mu \mathrm{g} / \mathrm{l}$ $(n, 0-1.7)$ and mercury $<1.0 \mu \mathrm{g} / \mathrm{l}(n, 0-5)$. Because of disease manifestation in adulthood, no analysis for FGF gene mutation was requested. FGF-23 readings were found increased fivefold and being $589 \mathrm{U} / 1$ (normal values, $26-110 \mathrm{U} / \mathrm{l})$. The whole body scintigraphy with somatostatin analogues 99mTc-tekrotyd $605 \mathrm{MBq}$ revealed intensive uptake of radiotracer in the right femoral head, and SPECT/CT demonstrated uptake in sclerotic bone lesion in the right femoral head-tumour intensively
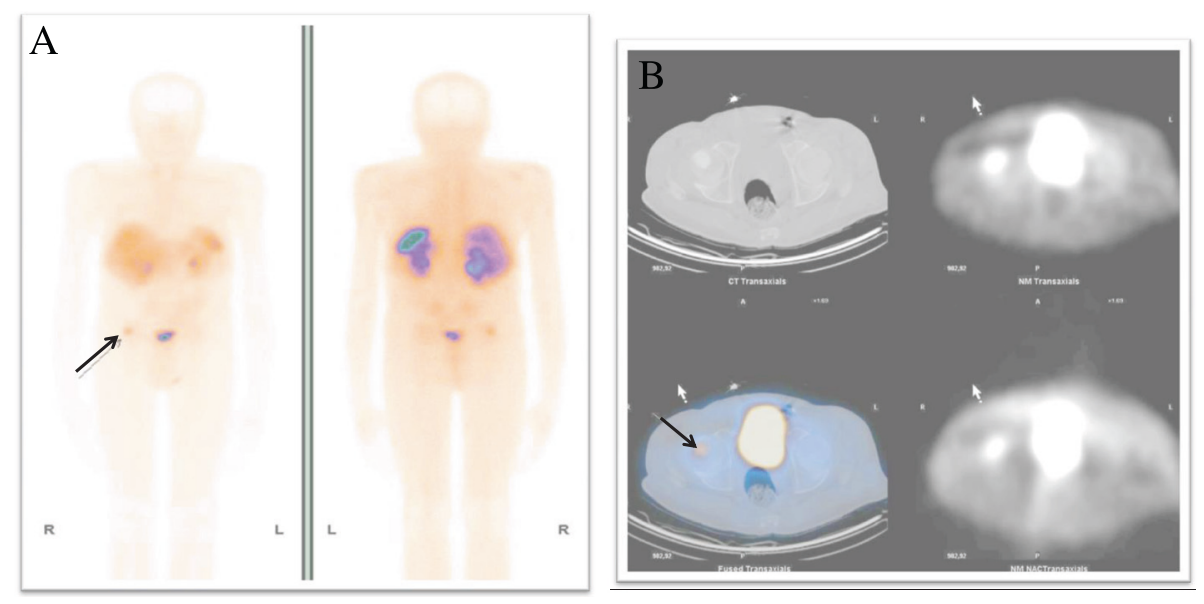

Fig. 3 a 99mTc-Tektrotyd SPECT /CT of a pelvis. Focal, intensive radio tracer uptake in right femoral head (long arrow) and b corresponding sclerotic lesion on CT (long arrow) (year 2014) 


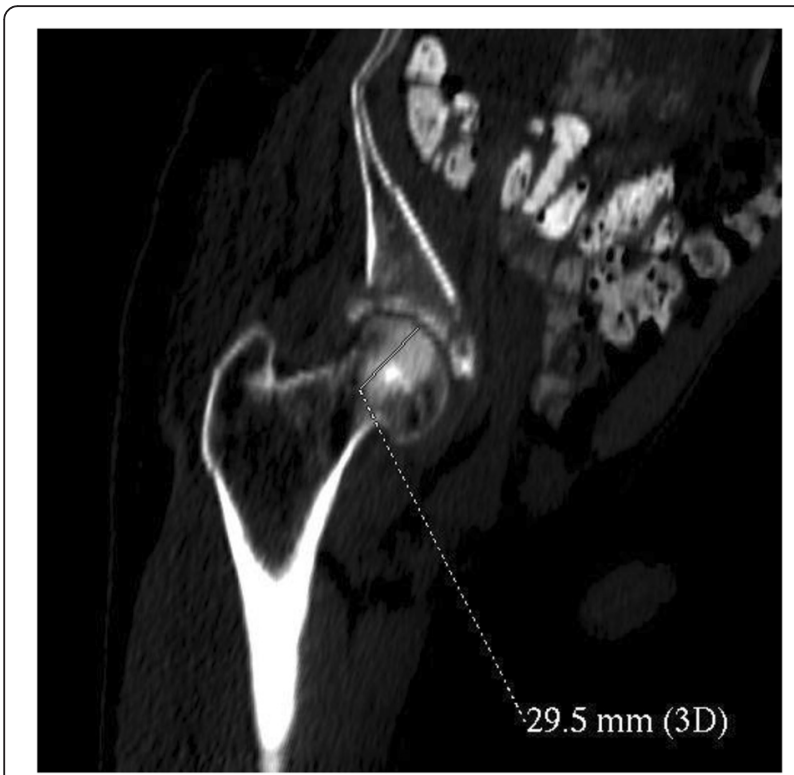

Fig. 4 Osteosclerotic tumour in the right femur head revealed during the whole body computerised tomography (year 2014)

expressing somatostatin receptors (Fig. 3). For possible multicentre tumour localization, the whole body CT was ordered. CT indicated deformations in skeletal bones, ribbons, thoracic vertebrae and pelvic bone due to osteomalacia or stress fractures, and no signs of healing were observed. CT also showed compressive fractures in Th3Th11 with pathologic kyphosis, stress fractures in both femoral heads and osteosclerotic tumour in right femur head (Fig. 4). No deformations were found in soft tissues, parenchymal organs, lungs or lymph nodes.

With strong prediction of phosphaturic mesenchymal tumour-induced osteomalacia, a tumour-removal surgery was performed, and subsequently, removal of the head and the neck of the right femur was required following total hip arthroplasty in October 2014. Surgical specimen was presented by femur proximal head. Examination revealed ill-defined intramedullary grey tumour, approximately $2 \mathrm{~cm}$ in diameter. Bone tissue was soft, macroscopically intact by tumour and showed a broad band of cartilage under articular surface. Histologic examination of the specimen revealed a hypercellular tumour composed of spindle-shaped cells in fibromyxoid matrix, with a hemangiopericytoma-like pattern. Tumour cells had clear to eosinophilic cytoplasm; nuclei were oval or elongated, of monomorphic appearance and with no signs of atypia. Mitotic figures were rare. Surrounding bone trabeculae were irregular in size and shape with wide osteoid seams and foci of hyaline cartilage, showing enchondral ossification. The tumour cells were strongly and diffusely positive with vimentin but exhibited no reactivity with PanCK, SMA, CD34, CD10 and D2-40 (Fig. 5).
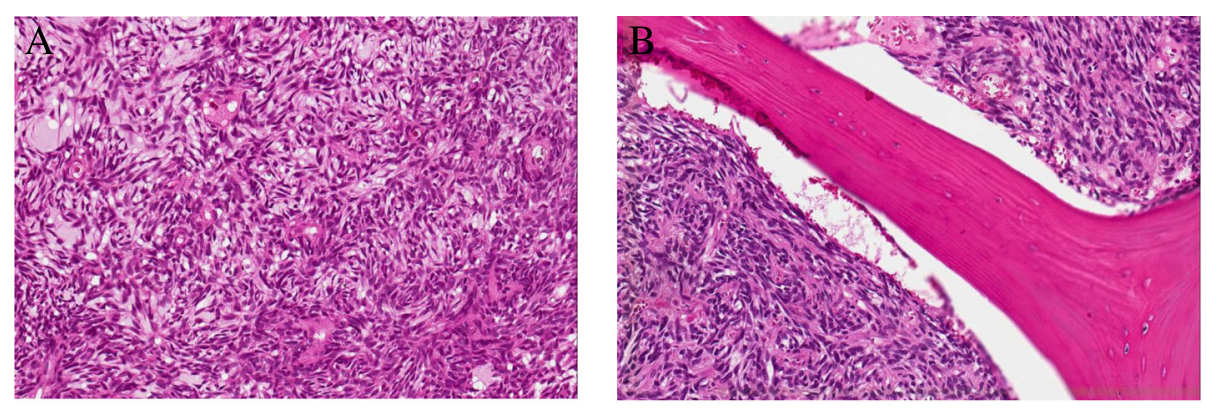

(HE 200x)
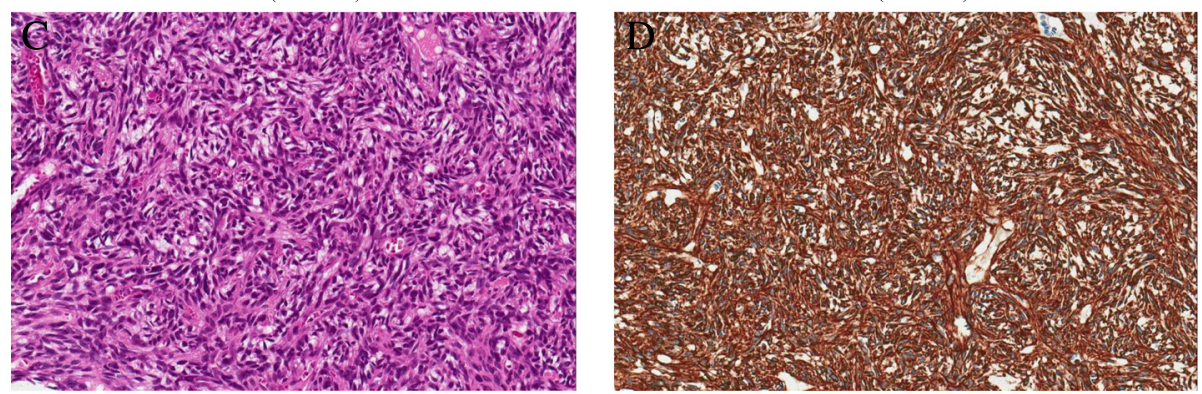

(HE 200x)

(Vimentin 200x)

Fig. 5 Histologic examination of the specimen revealed a hypercellular tumour composed of spindle-shaped cells in fibromyxoid matrix, with a hemangiopericytoma-like pattern (a). Tumour cells had clear to eosinophilic cytoplasm, nuclei were oval or elongated, of monomorphic appearance, with no signs of atypia. Mitotic figures were rarely seen. Surrounding bone trabeculae were irregular in size and shape with wide osteoid seams and foci of hyaline cartilage, showing enchondral ossification $(\mathbf{b}, \mathbf{c})$. The tumour cells were strongly and diffusely positive with vimentin (d) but exhibited no reactivity with PanCK, SMA, CD34, CD10 and D2-40 (year 2014) 
The post operation period went without clinical complications and after 3 months the levels of phosphorus, alkaline phosphatase and FGF-23 were measured. Alkaline phosphatase remained elevated 316 IU/l (40-150) with bone fraction now standing at $57.7 \%$ and FGF-23 returned to normal values $104 \mathrm{IU} / \mathrm{l}$ (26-110 IU/l). Three months after surgical procedure, the body pain almost disappeared and the weight increased up to $62 \mathrm{~kg}$ and height up to $166 \mathrm{~cm}\left(\mathrm{BMI}=22.5 \mathrm{~kg} / \mathrm{m}^{2}\right)$. The alkaline phosphatase returned to normal values 6 months after tumour extirpation and remained within normal values after 1 year of follow-up (Table 1). The phosphorus level increased remarkably up to $1.51 \mathrm{mmol} / \mathrm{l}$ (normal range, $0.87-1.45$ ) after 3 months and normalised within 1 year.

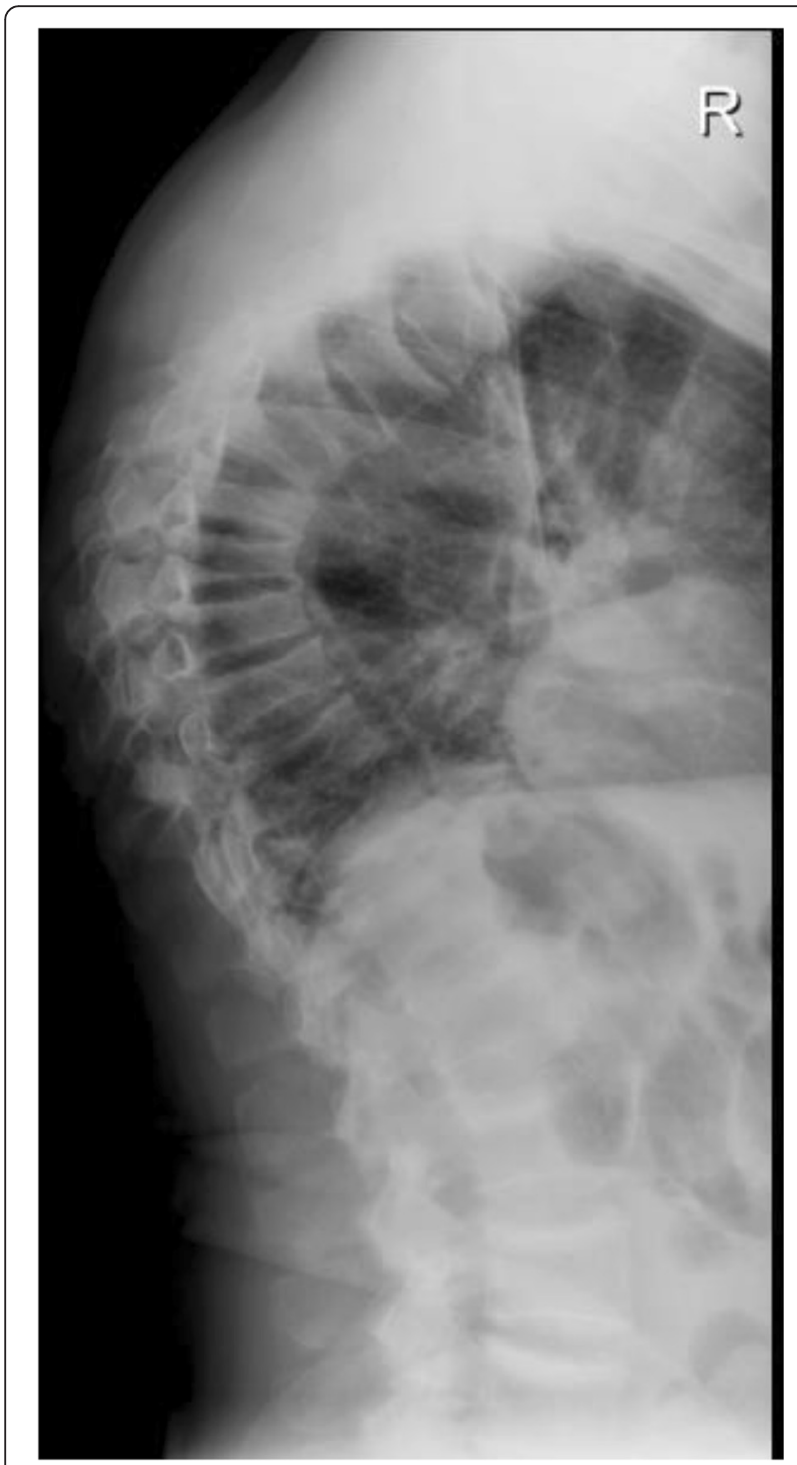

Fig. 6 Conventional radiography of the spine after 1 year after tumour resection showed permanent and nonreversible spine deformation due to the old compressions from Th3 to Th11 with no evidence of new compression fractures (year 2015)
We have to admit that measuring 24-h urinary phosphate was not a proper phosphate balance measure throughout the disease course. Without applying more sophisticated methods, e.g. percent tubular reabsorption of phosphate (\%TRP) or tubular maximum for phosphate corrected for glomerular filtration rate (TmP/ GFR) as it is recommended [16], significant loss of phosphate was probably missed from the beginning of disease. Conventional radiography of the spine after 1 year showed permanent and nonreversible spine deformation due to the old compressions from Th3 to Th11 with no evidence of new compression fractures (Fig. 6).

\section{Conclusions}

The diagnosis of TIO is a challenge under the best of circumstances. TIO should be included in the differential diagnosis in patients with progressive weakness, bone and muscle pain and multiple fractures. The diagnosis is commonly delayed for years due to the nonspecific nature of the presenting symptoms, failure to include determination of serum phosphorus levels in blood chemistry testing and difficulty in identifying the responsible tumour. The professional evaluation of whole body images, including single-photon emission tomography enables identification and better tumour contrast which can be found in skeletal structures of whatever region of the human body. FGF23 may be of help to understand the underlying mechanisms of TIO and a measurement to follow up the disease course.

\section{Ethics statement}

This review includes the description of one case report, and the consent form for publication was obtained from the person. The consent form of that particular person was sent to the Editor of this journal.

\section{Competing interests \\ The authors declare that they have no competing interests.}

\section{Authors' contributions}

All authors contributed equally within the limits and beyond their speciality in accumulating knowledge, diagnosing and managing this rare condition and have approved the manuscript. JD was involved in the disease management and follow-up of the patient. MM contributed to the patient management and had substantial involvement into the pathogenetical considerations of the biochemical mechanisms of the disease. DM was involved in the thorough literature review of tumour-induced osteomalacia. DV was involved in the radiological investigations throughout the follow-up. DS was involved in the histological evaluation of the tumour and proceeding of non-routine specimens. PB was involved in the surgical management and follow-up of the patient. TK revised the manuscript critically for important intellectual content and gave final approval for this manuscript version to be submitted.

\section{Acknowledgements}

We thank Prof. A. Venalis and Dr. D. Povilenaite for their intellectual input, support and conceptualization of this review. 


\section{Author details}

Faculty of Medicine, Vilnius University, Ciurlionio 21, Vilnius, Lithuania. ${ }^{2}$ Vilnius University Rheumatology Centre, Santariskiu 2, Vilnius, Lithuania. ${ }^{3}$ State Research Institute for Innovative Medicine, Zygimantu 9, Vilnius, Lithuania. ${ }^{4}$ Vilnius University Centre of Nephrology, Santariskiu 2, Vilnius, Lithuania. ${ }^{5}$ Vilnius University Radiology and Nuclear Medicine Centre, Santariskiu 2, Vilnius, Lithuania. ${ }^{6}$ National Centre of Pathology, Baublio 5, Vilnius, Lithuania. 'Vilnius University Hospital Santariskiu Klinikos Orthopaedic Traumatology Department, Santariskiu 2, Vilnius, Lithuania.

Received: 11 June 2015 Accepted: 30 December 2015 Published online: 08 January 2016

\section{References}

1. Deep NL, Cain RB, McCullough AE, Hoxworth JM, Lal D. Sinonasal phosphaturic mesenchymal tumor: case report and systematic review. Allergy Rhinol Provid RI. 2014;5(3):162-7.

2. Hamnvik O-PR, Becker CB, Levy BD, Loscalzo J. Clinical problem-solving. Wasting away N Engl J Med. 2014;370(10):959-66.

3. Folpe AL, Fanburg-Smith JC, Billings SD, Bisceglia M, Bertoni F, Cho JY, et al. Most osteomalacia-associated mesenchymal tumors are a single histopathologic entity: an analysis of 32 cases and a comprehensive review of the literature. Am J Surg Pathol. 2004;28(1):1-30.

4. Uramoto N, Furukawa M, Yoshizaki T. Malignant phosphaturic mesenchymal tumor, mixed connective tissue variant of the tongue. Auris Nasus Larynx. 2009;36(1):104-5.

5. Ledford CK, Zelenski NA, Cardona DM, Brigman BE, Eward WC. The phosphaturic mesenchymal tumor: why is definitive diagnosis and curative surgery often delayed? Clin Orthop. 2013;471(11):3618-25.

6. Sun Z, Jin J, Qiu G, Gao P, Liu Y. Surgical treatment of tumor-induced osteomalacia: a retrospective review of 40 cases with extremity tumors. BMC Musculoskelet Disord. 2015;16:43.

7. McCANCE RA. Osteomalacia with Looser's nodes (Milkman's syndrome) due to a raised resistance to vitamin $D$ acquired about the age of 15 years. Q J Med. 1947:16(1):33-46.

8. Casari S, Rossi V, Varenna M, Gasparini M, Parafioriti A, Failoni S, et al. A case of oncogenic osteomalacia detected by 111 In-pentetreotide total body scan. Clin Exp Rheumatol. 2003;21(4):493-6.

9. Clunie GP, Fox PE, Stamp TC. Four cases of acquired hypophosphataemic ('oncogenic') osteomalacia. Problems of diagnosis, treatment and long-term management. Rheumatol Oxf Engl. 2000;39(12):1415-21.

10. Dowman JK, Khattak FH. Oncogenic hypophosphataemic osteomalacia mimicking bone metastases on isotope bone scan. Ann Rheum Dis. 2006;65(12):1664

11. Fuentealba C, Pinto D, Ballesteros F, Pacheco D, Boettiger O, Soto N, et al. Oncogenic hypophosphatemic osteomalacia associated with a nasal hemangiopericytoma. J Clin Rheumatol Pract Rep Rheum Musculoskelet Dis. 2003:9(6):373-9.

12. Harbeck B, Schöcklmann H, Seekamp A, Czech N, Mönig H. Tumor-induced osteomalacia: successful treatment by radio-guided tumor surgery. J Clin Rheumatol Pract Rep Rheum Musculoskelet Dis. 2009;15(1):31-4.

13. Wang $H$, Zhong $D$, Liu $Y$, Jiang $Y$, Qiu G, Weng $X$, et al. Surgical treatments of tumor-induced osteomalacia lesions in long bones: seventeen cases with more than one year of follow-up. J Bone Joint Surg Am. 2015;97(13):1084-94.

14. Hesse E, Rosenthal H, Bastian L. Radiofrequency ablation of a tumor causing oncogenic osteomalacia. N Engl J Med. 2007:357(4):422-4.

15. Prader A, Illig R, Uehlinger $E$, Stalder $G$. Rickets following bone tumor. Helv Paediatr Acta. 1959;14:554-65.

16. Chong WH, Molinolo AA, Chen CC, Collins MT. Tumor-induced osteomalacia. Endocr Relat Cancer. 2011;18(3):R53-77.

17. Meyer RA, Meyer MH, Gray RW. Parabiosis suggests a humoral factor is involved in X-linked hypophosphatemia in mice. J Bone Miner Res Off J Am Soc Bone Miner Res. 1989;4(4):493-500.

18. Nesbitt T, Coffman TM, Griffiths R, Drezner MK. Crosstransplantation of kidneys in normal and Hyp mice. Evidence that the Hyp mouse phenotype is unrelated to an intrinsic renal defect. J Clin Invest. 1992;89(5):1453-9.

19. Miyauchi A, Fukase M, Tsutsumi M, Fujita T. Hemangiopericytoma-induced osteomalacia: tumor transplantation in nude mice causes hypophosphatemia and tumor extracts inhibit renal 25-hydroxyvitamin D 1-hydroxylase activity. J Clin Endocrinol Metab. 1988;67(1):46-53.
20. ADHR Consortium. Autosomal dominant hypophosphataemic rickets is associated with mutations in FGF23. Nat Genet. 2000;26(3):345-8.

21. White $K E$, Jonsson KB, Carn G, Hampson G, Spector TD, Mannstadt M, et al. The autosomal dominant hypophosphatemic rickets (ADHR) gene is a secreted polypeptide overexpressed by tumors that cause phosphate wasting. J Clin Endocrinol Metab. 2001:86(2):497-500.

22. Jan de Beur SM. Tumor-induced osteomalacia. JAMA. 2005;294(10):1260-7.

23. White KE, Larsson TE, Econs MJ. The roles of specific genes implicated as circulating factors involved in normal and disordered phosphate homeostasis: frizzled related protein-4, matrix extracellular phosphoglycoprotein, and fibroblast growth factor 23. Endocr Rev. 2006; 27(3):221-41.

24. Carpenter TO. The expanding family of hypophosphatemic syndromes. J Bone Miner Metab. 2012;30(1):1-9.

25. Shimada T, Hasegawa H, Yamazaki Y, Muto T, Hino R, Takeuchi Y, et al. FGF-23 is a potent regulator of vitamin D metabolism and phosphate homeostasis. J Bone Miner Res Off J Am Soc Bone Miner Res. 2004;19(3):429-35.

26. Ramon I, Kleynen P, Body J-J, Karmali R. Fibroblast growth factor 23 and its role in phosphate homeostasis. Eur J Endocrinol Eur Fed Endocr Soc. 2010;162(1):1-10.

27. Liu S, Quarles LD. How fibroblast growth factor 23 works. J Am Soc Nephrol JASN. 2007:18(6):1637-47.

28. Shimada T, Mizutani S, Muto T, Yoneya T, Hino R, Takeda S, et al. Cloning and characterization of FGF23 as a causative factor of tumor-induced osteomalacia. Proc Natl Acad Sci U S A. 2001;98(11):6500-5.

29. Hannan FM, Athanasou NA, Teh J, Gibbons CLMH, Shine B, Thakker RV. Oncogenic hypophosphataemic osteomalacia: biomarker roles of fibroblast growth factor 23, 1,25-dihydroxyvitamin D3 and lymphatic vessel endothelial hyaluronan receptor 1. Eur J Endocrinol Eur Fed Endocr Soc. 2008;158(2):265-71.

30. Hu F-K, Yuan F, Jiang C-Y, Lv D-W, Mao B-B, Zhang Q, et al. Tumor-induced osteomalacia with elevated fibroblast growth factor 23: a case of phosphaturic mesenchymal tumor mixed with connective tissue variants and review of the literature. Chin J Cancer. 2011:30(11):794-804.

31. Weidner N. Review and update: oncogenic osteomalacia-rickets. Ultrastruct Pathol. 1991:15(4-5):317-33.

32. Leaf DE, Pereira RC, Bazari $H$, Jüppner $H$. Oncogenic osteomalacia due to FGF23-expressing colon adenocarcinoma. J Clin Endocrinol Metab. 2013; 98(3):887-91.

33. Duet $M$, Kerkeni S, Sfar R, Bazille C, Lioté F, Orcel P. Clinical impact of somatostatin receptor scintigraphy in the management of tumor-induced osteomalacia. Clin Nucl Med. 2008:33(11):752-6

34. Haeusler G, Freilinger M, Dominkus M, Egerbacher M, Amann G, Kolb A, et al. Tumor-induced hypophosphatemic rickets in an adolescent boy-clinical presentation, diagnosis, and histological findings in growth plate and muscle tissue. J Clin Endocrinol Metab. 2010;95(10):4511-7.

35. Houang M, Clarkson A, Sioson L, Elston MS, Clifton-Bligh RJ, Dray M, et al. Phosphaturic mesenchymal tumors show positive staining for somatostatin receptor 2A (SSTR2A). Hum Pathol. 2013:44(12):2711-8.

36. Ogose A, Hotta T, Emura I, Hatano H, Inoue Y, Umezu H, et al. Recurrent malignant variant of phosphaturic mesenchymal tumor with oncogenic osteomalacia. Skeletal Radiol. 2001;30(2):99-103.

37. Jiang $Y$, Xia W, Xing X, Silva BC, Li M, Wang O, et al. Tumor-induced osteomalacia: an important cause of adult-onset hypophosphatemic osteomalacia in China: report of 39 cases and review of the literature. J Bone Miner Res Off J Am Soc Bone Miner Res. 2012;27(9):1967-75.

38. Gardner $\mathrm{KH}$, Shon W, Folpe AL, Wieland CN, Tebben PJ, Baum CL. Tumor-induced osteomalacia resulting from primary cutaneous phosphaturic mesenchymal tumor: a case and review of the medical literature. J Cutan Pathol. 2013:40(9):780-4. quiz 779.

39. Seijas R, Ares O, Sierra J, Pérez-Dominguez M. Oncogenic osteomalacia: two case reports with surprisingly different outcomes. Arch Orthop Trauma Surg. 2009;129(4):533-9.

40. Lewiecki EM, Urig EJ, Williams RC. Tumor-induced osteomalacia: lessons learned. Arthritis Rheum. 2008;58(3):773-7

41. Hautmann AH, Schroeder J, Wild P, Hautmann MG, Huber E, Hoffstetter P, et al. Tumor-induced osteomalacia: increased level of FGF-23 in a patient with a phosphaturic mesenchymal tumor at the tibia expressing periostin. Case Rep Endocrinol. 2014;2014:729387.

42. Ogura E, Kageyama K, Fukumoto S, Yagihashi N, Fukuda Y, Kikuchi T, et al. Development of tumor-induced osteomalacia in a subcutaneous tumor, 
defined by venous blood sampling of fibroblast growth factor-23. Intern Med Tokyo Jpn. 2008;47(7):637-41.

43. Seufert J, Ebert K, Müller J, Eulert J, Hendrich C, Werner E, et al. Octreotide therapy for tumor-induced osteomalacia. N Engl J Med. 2001;345(26):1883-8.

44. Chong WH, Yavuz S, Patel SM, Chen CC, Collins MT. The importance of whole body imaging in tumor-induced osteomalacia. J Clin Endocrinol Metab. 2001;96(12):3599-600.

45. Dissanayake AM, Wilson JL, Holdaway IM, Reid IR. Oncogenic osteomalacia: culprit tumour detection whole body magnetic resonance imaging. Intern Med J. 2003;33(12):615-6

46. Jan de Beur SM, Streeten EA, Civelek AC, McCarthy EF, Uribe L, Marx SJ, et al. Localisation of mesenchymal tumours by somatostatin receptor imaging. Lancet. 2002;359(9308):761-3.

47. Moran M, Paul A. Octreotide scanning in the detection of a mesenchymal tumour in the pubic symphysis causing hypophosphataemic osteomalacia. Int Orthop. 2002;26(1):61-2.

48. Dupond JL, Mahammedi H, Prié D, Collin F, Gil H, Blagosklonov O, et al. Oncogenic osteomalacia: diagnostic importance of fibroblast growth factor 23 and F-18 fluorodeoxyglucose PET/CT scan for the diagnosis and follow-up in one case. Bone. 2005;36(3):375-8.

49. Andreopoulou P, Dumitrescu CE, Kelly MH, Brillante BA, Cutler Peck CM, Wodajo FM, et al. Selective venous catheterization for the localization of phosphaturic mesenchymal tumors. J Bone Miner Res Off J Am Soc Bone Miner Res. 2011;26(6):1295-302.

50. Jagtap VS, Sarathi V, Lila AR, Malhotra G, Sankhe SS, Bandgar T, et al. Tumor-induced osteomalacia: a single center experience. Endocr Pract Off $J$ Am Coll Endocrinol Am Assoc Clin Endocrinol. 2011;17(2):177-84.

51. Agrawal K, Bhadada S, Mittal BR, Shukla J, Sood A, Bhattacharya A, et al. Comparison of 18F-FDG and 68Ga DOTATATE PET/CT in localization of tumor causing oncogenic osteomalacia. Clin Nucl Med. 2015;40(1):e6-10.

52. Rhee Y, Lee JD, Shin KH, Lee HC, Huh KB, Lim SK. Oncogenic osteomalacia associated with mesenchymal tumour detected by indium-111 octreotide scintigraphy. Clin Endocrinol (Oxf). 2001;54(4):551-4.

53. Rodrigues NR, Calich AL, Etchebehere M, Ichiki WA, Pereira FP, Amstalden EMI, et al. Whole-body (99m)Tc-octreotide scintigraphy with SPECT/CT to detect occult tumor inducing paraneoplastic osteomalacia. Clin Nucl Med. 2015:40(1):54-7.

54. Antunes P, Ginj M, Zhang H, Waser B, Baum RP, Reubi JC, et al. Are radiogallium-labelled DOTA-conjugated somatostatin analogues superior to those labelled with other radiometals? Eur J Nucl Med Mol Imaging. 2007;34(7):982-93.

55. Khosravi A, Cutler CM, Kelly MH, Chang R, Royal RE, Sherry RM, et al. Determination of the elimination half-life of fibroblast growth factor-23. J Clin Endocrinol Metab. 2007;92(6):2374-7.

56. Harvey JN, Gray C, Belchetz PE. Oncogenous osteomalacia and malignancy. Clin Endocrinol (Oxf). 1992;37(4):379-82.

57. Paglia F, Dionisi S, Minisola S. Octreotide for tumor-induced osteomalacia. N Engl J Med. 2002;346(22):1748-9. author reply 1748-9.

58. Geller JL, Khosravi A, Kelly MH, Riminucci M, Adams JS, Collins MT. Cinacalcet in the management of tumor-induced osteomalacia. J Bone Miner Res Off J Am Soc Bone Miner Res. 2007;22(6):931-7.

59. Aono Y, Yamazaki Y, Yasutake J, Kawata T, Hasegawa H, Urakawa I, et al. Therapeutic effects of anti-FGF23 antibodies in hypophosphatemic rickets/osteomalacia. J Bone Miner Res Off J Am Soc Bone Miner Res. 2009; 24(11):1879-88.

60. Carpenter TO, Imel EA, Ruppe MD, Weber TJ, Klausner MA, Wooddell MM, et al. Randomized trial of the anti-FGF23 antibody KRN23 in X-linked hypophosphatemia. J Clin Invest. 2014;124(4):1587-97.

61. Kinoshita Y, Fukumoto S. Anti-FGF23 antibody therapy for patients with tumor-induced osteomalacia. Clin Calcium. 2014;24(8):1217-22.

\section{Submit your next manuscript to BioMed Central and we will help you at every step:}

- We accept pre-submission inquiries

- Our selector tool helps you to find the most relevant journal

- We provide round the clock customer support

- Convenient online submission

- Thorough peer review

- Inclusion in PubMed and all major indexing services

- Maximum visibility for your research

Submit your manuscript at www.biomedcentral.com/submit
Biomed Central 